\title{
SOCIO-TECHNICAL STUDIES OF MOBILITY AND UBIQUITY
}

\author{
Carsten Sørensen \\ London School of Economics and Political Science \\ London, United Kingdom \\ Youngjin Yoo \\ Case Western Reserve University \\ Cleveland, OH U.S.A.
}

\section{INTRODUCTION}

This proceedings on socio-technical issues and challenges in designing ubiquitous information environments represents the first IFIP Working Group 8.2 conference dedicated to mobile and ubiquitous computing. It is, furthermore, only the third time an IFIP 8.2 Working Conference has been organized around an emerging information technology. In 1989, the working conference was dedicated to the technology of that time: desktop information technology. In 1992, the conference investigated the practices of using computer-aided software engineering (CASE) tools for software development. The 2005 conference is related to the 1989 conference in that the maturity of ubiquitous computing today is at about the same level as desktop computing technology was in 1989.

In 2004, IFIP Working Group 8.2 marked the $20^{\text {th }}$ anniversary of the Manchester Conference, the landmark for research methods in information systems. Perhaps it is fitting that we dedicate the entire 2005 conference to the emerging technology of our time, thereby marking the first conference in the third decade of IFIP Working Group 8.2's history. In the first decade, IFIP Working Group 8.2 welcomed computers into our offices and onto our desks in 1989; in the second, we let them out into the world.

The rapid developments in mobile and wireless communication technologies and the continuing miniaturization of computing devices makes ubiquitous information environments more a technical reality than a distant vision. Ubiquitous computing as the next wave of organizational computing offers new possibilities and opportunities for organizations to improve their productivity and effectiveness. Companies such as FedEx and UPS are investing millions of dollars to upgrade their wireless network 
infrastructure, bringing information about packages, trucks, and couriers ever closer to their customers. Retail giant Wal-Mart is actively exploring the various mobile technologies such global positioning systems (GPS) and radio frequency identification (RFID) tags to improve its operations. Millions of customers in countries such as Japan and Korea have signed up for broadband cellular phone services to exchange video clips and download their favorite music. Companies in those countries are experimenting with the tight integration of mobile technologies into their core products and services. Scandinavian and European countries provide extensive mobile services supporting users in mobile banking, payments, and other business and personal services. Progressive Insurance, an American auto insurance company, has experimented with GPS in order to implement a usage-based premium system, and GM's OnStar service provides service support and other online services for automobile drivers. For the majority of workers, a mobile phone is now a natural part of their daily work. For an increasing proportion, the mobile phone is accompanied by a laptop.

However, the emergence of ubiquitous information environments not only signals opportunities, but also fundamentally challenges many of the traditional assumptions about organizations, management, computing, communication, and work. The increased mobility in ubiquitous information environments will bring about new socially defined meanings of issues such as the temporal and spatial aspects of organizational behavior. The unprecedented scale of deployment of wireless tools and sensors embedded in the environment challenges our understanding of technology acceptance and scale of operation in organizations. Technologies such as GPS and RFID are examples of increased attempts to bridge the gap between the physical and representations of the physical. The personalization and the pervasive nature of these tools and their linking of worlds will blur the boundaries between social and technical aspects of organizational computing.

While organizations are rapidly adopting various types of ubiquitous computing applications, there is a dearth of careful scholarly work examining the social dimensions related to the design and implementation of such computing environments. There is a range of research of a more technical nature exploring technical possibilities or evaluating the usability of various systems and prototypes. Given that ubiquitous information environments are relatively recent phenomena in terms of general adoption outside experimental settings, the relative lack of published work is perhaps not surprising. However, it is a unique opportunity for the IFIP Working Group 8.2 community of scholars to take active part in the development and use of technology in society at large. The development of ubiquitous computing not only opens up new research issues and topics to the Information Systems research community; it also invites us to revisit the classical concerns studied by the Group since its inception (Lyytinen and Yoo 2002; Lyytinen et al. 2004). The papers included in this volume cover investigations of both these endeavors.

A set of emerging information and communication technologies (ICTs) will interactively inspire and demand new social arrangements, just as social innovation will spark technological innovation. This does not, however, necessarily signal radical changes across the board. Although the emergence of PC technology signaled farewell to some old organizational roles and the emergence of new ones, it did not change all social aspects. The desktop information technology provided a vehicle for individual information and communication management in the office-or at home. It created a 
closer link between the individual and computer, personalizing the relationship. The best examples of this are spreadsheet and word processing applications. Ubiquitous information environments heralds an even closer bond between technical artifacts and social actions. This calls for a fundamental understanding of the social consequences of the technological properties as well as the technical opportunities and challenges of emerging social practices. The ubiquitous information environment not only links the individual and ICTs more tightly together in specific contexts, it seeks to transcend contexts as well as to actively employ computational awareness of these contexts.

\section{BACKGROUND TO TOPIC}

It could be argued that Lars Magnus Ericsson building a telephone for his wife Hilda's car in 1910 marked the beginning of a new era, even if its use required Hilda stopping the car and connecting the phone to telephone wires (Agar 2003, p. 8). It was, however, two-way closed radio systems sharing frequencies for the military and police forces during the 1930 s and 1940 s that marked the first significant implementation. Development of LCD displays, small powerful batteries, integrated circuits, and the reuse of frequencies through dividing areas into cells paved the way for the mobile phone-or the cell phone as it is called in the United States (Agar 2003). In the late 1960s and early 1970s, at the time of large, monolithic mainframes, Alan Kay and others from Xerox Parc formulated the conceptual design of the Dynabook, which in essence was a notebook or tablet computer. The Dynabook represented a conceptual leap in the understanding of how computers ought to support human activities. Another Xerox Parc researcher, Mark Weiser, was the first to properly formulate a vision of ubiquitous information environments in his Scientific American article from 1991 (see also Weiser 1999). Ubiquitous information environments imply the social embedding of mobile and pervasive technologies. Mobile technologies such as laptops, notebooks, mobile phones, personal digital assistants (PDAs), and smart-phones enable the user to access people and information sources while on the move. Pervasive technologies denote embedding computers in the environment beyond general purpose computing devices, as well as utilizing environmental and contextual information in the services offered.

Ubiquitous information environments signal the further development of computing and networking technologies where the computer has been subjected to miniaturization from the large mainframe to the PC to the laptop, tablet PC, PDA and smart-phone. Networking technology has evolved from the era of unconnected computers, through local area networks and wide area networks, to our current situation where several complementing and competing networking standards span the globe. Personal area networks (PANs) such as Bluetooth, Ultra Wide Band, and Zigbee offer device interconnectivity in close proximity. Local area network standards such as WiFi (IEEE $822.11 . \mathrm{a} / \mathrm{b} / \mathrm{g} /$ ) provide medium-range wireless connectivity, and standards such as GSM, $3 \mathrm{G}$, and WiMAX provide wide area wireless connectivity. Such rapid development of network technology has expanded the reach of computers around the globe, while at the same time bringing it ever more intimately into our everyday experience.

Simultaneously, with the emergence of smaller and increasingly pervasive computing technologies sporting a variety of wireless networking possibilities, day-to-day social activities have undergone significant change. The emergence of large geo- 
graphically distributed organizations such as railway or oil companies from 1850 to 1920 led to the birth of scientific management (Yates 1989). The organization and management of work and the use of various technologies supporting this coevolved and formed the foundation for the introduction of mechanical and electronic computing equipment (Caminer et al. 1998; Yates 1989). Organizational changes during the 1980s aimed at meeting market demands for innovation led to phenomena such as internal markets, matrix organizations, concurrent engineering, and process reengineering (Kunda, 1992; Malone, 2004). These new ways of working attempted to alter previous organizational arrangements in order to support more direct connections among participants. Individual offices in many cases turned into cubicles and open-plan offices in order to support more fluid and ad hoc interaction. This has led to a significant amount of research into work, and indeed society as a whole, on networking (Castells 1996; Hinds and Kiesler 2002; Sproull and Kiesler 1993). One particular aspect of this is the understanding of remote and mobile working enabled and supported by ubiquitous information environments, for example by repair engineers or professionals (Barley and Kunda 2004; Kakihara 2003; Ljungberg 1997; Orr 1996; Wiberg 2001).

New working arrangements such as flexible working with home offices or hotdesking, remote working across branches or between continents, and mobile individuals working in the field are all examples of intricate configurations of working practices and ICT. New configurations of working practices and technologies have raised many challenging issues, including how to design appropriate working environments combining the two (Bjerrum and Nielsen 2003; Duffy et al. 1993; Laing et al. 1998; Schultze and Orlikowski 2004), how to maintain social relationships (Jarvenpaa and Leidner, 1999), provide leadership (Yoo and Alavi 2004), exercise remote control (Wiredu 2005), support for cognition (Boland et al. 1994), and how to engage and disengage mobile technologies (Sørensen and Pica 2005). The consequences of these emerging practices are still far from clear, but there are strong signs of increasing pressures on people to be constantly available and efficient (Bunting 2004). Understanding ubiquitous information environments in the context of modern working practices is critical in order to grasp the complex interactions between individual, organizational, and infrastructural issues. Human-computer interaction in collaborative work has been investigated by the HCI and CSCW communities (Dix and Beale 1996; Dourish 2001; Heath and Luff 2000; Lasen and Hamill 2005), as well as several academic journals such as Personal and Ubiquitous Computing. However, much of this research does not reconnect the debate to a concern for organizational performance.

In a broader context, it is equally important to understand the possibilities and consequences of ubiquitous information environments in everyday life beyond the confined boundary of work. The technologies and their use in the context of work have precisely contributed to the softening of barriers between working life and home life and emphasized an established trend (Brown et al. 2001; Bunting 2004; Hochschild 1997). It is in this area in particular that we find a significant body of research exploring the impact of, primarily, the mobile phone on social relations in general (Brown et al. 2001; Rheingold 2002). Much of this is broadly sociologically informed inquiries where the specific technical characteristics as well as the organizational consequences play a minor role compared to the overall social consequences (Cooper et al. 2002; Katz and Aakhus 2002; Kopomaa 2000; Ling 2004; Ling and Pedersen 2005). This strand of research will, as opposed to CSCW and IS research, often consider consequences broader than 
in the context of work, and theorize the much broader social issues such as a sociology of the mobile (Urry 2000, 2003).

Aside from those already mentioned, a broad range of disciplines have addressed the socio-technical developments related to ubiquitous information environments in general and the global diffusion of mobile phones in particular. These range from the obvious strictly technical or engineering concerns for devising the technical services and infrastructures (Baresi et al. 2004; Schiller and Voisard 2004; Umar 2004), to the study of the role of global infrastructure standards (Brunsson et al. 2000; Funk 2002), to architecture, arts, and aesthetics perspectives on ubiquitous information environments (Hoete 2003; Lovink and Gerritzen 2002; McCollough 2004)

Given the significance of the development and use of ubiquitous information environments, the wide range of issues raised must be met by a variety of perspectives and inquiry approaches. The IFIP Working Group 8.2 community is clearly able to provide a valuable contribution to this debate, both in terms of understanding the general sociotechnical opportunities and impact, but perhaps more specifically in terms of addressing the issues of embedding these technologies in the context of organizational life.

\section{THE REVIEW PROCESS}

A total of 46 papers were submitted to the conference organizers. The papers were submitted from all over the globe, with 15 papers from AIS region 1 (the Americas), 25 from AIS region 2 (Europe, Middle East, and Africa), and 6 from AIS region 3 (Asia and the Pacific). Both program chairs managed all 46 papers together. In the few cases of past or previous shared affiliation between an author and one of the chairs, the other program chair was responsible for that particular paper. Each paper was allocated two reviewers recruited from the program committee, authors and selected members of the IFIP Working Group 8.2 community at large. The members of the program committee reviewed up to two papers each. We wish to express our gratitude to Matt Germonprez, University of Wisconsin, who at the time was at Case Western Reserve, and his graduate student, Brian Warner. They installed and managed an open source system enabling us to manage the entire submission and review process electronically over the Web. After minor issues of enrolling reviewers, the system worked remarkably well and it allowed us to accept the submissions, track reviews, and prepare final letters to the authors. After considering all of the reviews by the members of the Program Committee and the reviewers, we accepted 20 full papers and 3 position papers. We also invited four panels. The final selection of papers represents diverse theoretical and empirical perspectives on ubiquitous information environments.

\section{OVERVIEW OF THE PAPERS}

\subsection{Keynotes}

This volume includes extended abstracts of the keynotes by Thomas W. Malone (MIT), Lee Green (IBM), and Paul Durish (University of California, Irvine). We have 
chosen these three keynote speakers in part to emphasize the rich and diverse perspectives that can enrich our discourse on ubiquitous information environments. Picking up the theme of his recent book, in his talk "The Future of Work," Malone puts forward his view on how the development of information and communication technologies and the subsequent reduction of communication cost fundamentally alter the conditions for how we organize work. Although ubiquitous information environments have yet not reached their full potential, his views certainly invite us to ponder the impact of ubiquitous information environments on the organization of work. Green is responsible for IBM's worldwide product and identity design strategy. In his talk, "Its the Experience, Not the Price," Green discusses how IBM shifts its attention from hardware to experiences in dealing with customers' ubiquitous information environment needs. Building on IBM's recent projects with the Mayo Clinic and the New York Stock Exchange, Green illustrates how a design perspective can be a powerful lens for much more dynamic and complex requirements in ubiquitous information environments. Finally, Dourish's presentation, "The Culture of Information: Ubiquitous Computing and Representations of Reality," begins with the premise that movement toward ubiquitous information environments is more than mere changes in the computing platforms. Instead, he argues, the shift represents a fundamental transformation of our everyday experiences into "embodied interactions" that draws on physical, social, and cultural practices (Dourish 2001).

\subsection{Papers}

The accepted papers cover a wide range of topics drawing on an extremely rich set of theoretical perspectives. They are grouped into four categories: (1) papers exploring the use and consequences of ubiquitous information environments at the individual level; (2) research into the organizational consequences of ubiquitous information environments; (3) papers focusing on the development and integration of ubiquitous information environments; and (4) investigations of the challenges related to macro-level and institutional issues in the innovation and diffusion of ubiquitous information environments.

\subsubsection{Individual Consequences}

This section includes four papers exploring individual use of and experiences with ubiquitous information environments. The section begins with two papers examining the relationship between technology use and social life from two different perspectives. In their paper, "Friend or Foe? The Ambivalent Relationship between Mobile Technology and its Users," Sirkka L. Jarvenpaa, Karl Reiner Lang, and Virpi Kristiina Tuunainen explore how the use of mobile technologies create not only opportunities but also tensions in individuals. Through 33 focus group sessions in Finland, Japan, Hong Kong, and the United States, they explore various aspects of this paradox and offer a useful framework outlining the individual paradoxes in mobile technology use. Jeria L. Quesenberry and Eileen M. Trauth examine in their paper, "The Role of Ubiquitous Computing in Maintaining Work-Life Balance: Perspectives from Women in the IT 
Workforce," the potential of ubiquitous computing to address the work-life balance from the perspective of women in the IT workforce. The empirical evidence for identifying the three key themes related to the potential benefit of ubiquitous information environments in addressing work-life balance issues for women is provided by 45 interviews. These themes are asynchronous communication, social networks, and personal life benefits.

The final two papers in this section extend user technology acceptance, one of the best-explored topics in the IS field, into the study of ubiquitous information environments. In their paper, "Reflexivity, the Social Actor, and M-Service Domestication: Linking the Human, Technological, and Contextual," Jennifer Blechar, Lars Knutsen, and Jan Damsgaard explore, based on an on-going field-study, how individual actors' own reflexivity and how on-going self-monitoring influences the adoption and domestication of mobile commerce services. In their paper, "Privacy Considerations in Location-Based Advertising," Heng Xu and Hock-Hai Teo also explore the adoption of mobile commerce services, but from a privacy perspective. They conducted an experimental study to test their hypotheses.

\subsubsection{Organizational Impact}

The eight papers in this section explore various challenges and consequences of ubiquitous information environments at the organizational level. The first four papers report experiences from different organizations that have adopted different ubiquitous information environments. The paper by Henrique M. G. Martins and Matthew R. Jones, "Mobility in the Round: Use of Wireless Laptop PCs in Clinical Ward Rounds," explores why a significant portion of doctors had never used the technology five years after the initial introduction. Their paper reveals how ubiquitous information environments need to adapt to the local and situated needs of individual users. Andrea Tapia and Steve Sawyer draw on their field study of mobile computing in the criminal justice system in their paper "Beliefs about Computing: Contrary Evidence from a Study of Mobile Computing Use among Criminal Justice Personnel." The paper explores how technology determinism can act as a belief system for individual users. The authors were struck by the persistent positive beliefs of the vision of mobile computing among the users in the trial, even though the device, applications, and network systems never worked as originally intended. The paper by Magnus Andersson, Rikard Lindgren, and Ola Henfridsson, entitled "Assessing the Mobile-Stationary Divide in Ubiquitous Transport Systems," focuses on the division between stationary office systems and mobile applications. The two technological systems have evolved from different innovation regimes and this is argued as a primary challenge in deploying enterprisewide ubiquitous information environments. Anand Ramchand, Paul Raj Devadoss, and Shan L. Pan report from a case study of RFID implementation at Singapore's National Library Board. Their paper, "The Impacts of Ubiquitous Computing Technologies on Business Process Change and Management: The Case of Singapore's National Library Board," provides valuable insight into the social and organizational consequences of RFID deployment in organizations.

This section also includes two papers that explore the possibility of creating distributed socio-technical networks of distributed resources through ubiquitous 
information environments. Katrin Jonsson and Jonny Holmström in their paper, "Ubiquitous Computing and the Double Immutability of Remote Diagnostics Technology: An Exploration into Six Cases of Remote Diagnostics Technology Use," explore this using actor-network theory. They report from a case study of the use of remote diagnostic technology to create a distributed socio-technical network of knowledge resources. The paper, "Wireless Grids: Assessing a New Technology from a User Perspective," by Lee W. McKnight, Raed M Sharif, and Lidwien van de Wijngaert discusses the potential efficacy of wireless grids as a way of creating ad hoc networks for sharing resources. They do so through content analysis of the results of two focus group meetings.

The final two papers focus on the impact of mobility on work practices and activities. Masao Kakihara's paper, "Fluid Organizing of Work in the Ubiquitous Information Environment," explores structural changes in organizing work practices in the context of mobile professional work. He presents the notion of "fluid organizing" based on his field work in Japan. Gamel Wiredu, in "The Reconstruction of Portable Computers: On the Flexibility of Mobile Computing in Mobile Activities," draws on activity theory in his discussion of how work activities can be transformed through the use of mobile devices. Based on a field study of a mobile application for computermediated learning, he argues that the transformative capability of mobile devices is determined by affordances, motives, and modalities of mobility.

\subsubsection{Development Issues}

This section includes four papers dealing with various social issues related to the development of ubiquitous information environments. The first paper by Jens Henrik Hosbond and Peter Axel Nielsen, "Mobile Systems Development: A Literature Review," provides an extensive review of the mobile systems development literature. Hosbond and Nielsen suggest, that in order to provide a useful basis for mobile systems development, traditional systems development research needs expanding both in terms of its technology perspective (from stationary to mobile) as well as in terms of its organizational perspectives (from project based to interorganizational). The paper by Carl Magnus Olsson and Ola Henfridsson, entitled "Designing Context-Aware Interaction: An Action Research Study," reports the results from an action research study on the design of context-aware computing environments. Conceptualizing a car as a platform for ubiquitous information environments, the project developed and tested design principles for context-aware applications. The paper illustrates new challenges of designing applications for ubiquitous information environments.

The final two papers in this section focus on the design and development of information infrastructure necessary in order to facilitate effective ubiquitous information environments. Panos Constantinides and Michael Barrett, in their paper, "Approaching Information Infrastructure as an Ecology of Ubiquitous Sociotechnical Relations," develop an analytical framework of information infrastructure as an ecology of ubiquitous socio-technical relations with seven layers. Their framework illustrates the complex social reality of designing, developing, and maintaining ubiquitous information environments and how configurations among different social actors in organizations can shape and influence the ways in which technical infrastructure and tools necessary 
for ubiquitous information environments are interrelated with each other. The paper by Gunnar Ellingsen and Eric Monteiro, "The Slight Surprise of Integration," reports from a case study of the implementation of a new information infrastructure at a university hospital in Northern Norway. Their discussion on the unintended consequences of integrating new technological infrastructures help us understand the social and organization challenges of creating ubiquitous information environments providing "seamless" integration of diverse computing resources.

\subsubsection{Innovation and Diffusion of Ubiquitous Information Environments}

This section includes four papers that broadly deal with innovation and diffusion of ubiquitous information environments. The first three papers explore institutional and interorganizational issues affecting the diffusion of ubiquitous information environments. In the paper "Scaling the Wall: Factors Influencing the Conditions of Market Entry in the Mobile Data Market," Annemijn F. van Gorp, Carleen F. Maitland, and Brian $\mathrm{H}$. Cameron investigate the relationships between information providers and the powerful mobile service operators and discuss how such a relationship affects the diversity of information services. Shirley Chan, Heejin Lee, and Sangjo Oh explore the diffusion of innovations in China through the lens of disputes over standards. Their paper, "An International Mobile Security Standard Dispute: From the Actor-Network Perspective," examines the diffusion of how the innovation of a mobile security standard is being shaped and negotiated among social actors that represent national interests as well as different technological regimes. Steinar Kristoffersen, Petter Nielsen, Jennifer Blechar, and Ole Hanseth explore the coordination among different actors in the mobile services value network in the paper, "Ordinary Innovation of Mobile Services." Drawing on three case studies, they argue that existing theories cannot fully explain the innovation of mobile services.

Finally, Melanie Wilson's paper, "The Ubiquity and Utility of Resistance: Codesign and Personalization of Information Systems," puts forward the view that user resistance provides a site for personalization and local adaptation. She critically analyzes the term ubiquity and seeks to offer an alternative theoretical perspective to examine the role of users in the innovation of ubiquitous information environments.

\subsection{Position Papers}

The three accepted position papers explore various aspects of ubiquitous information environments. In the paper, "CrackBerries: The Social Implications of Ubiquitous Wireless E-Mail Devices," Melissa A. Mazmanian, Wanda J. Orlikowski, and JoAnne Yates outline a research agenda for studying how mobile e-mail devices find a place in the lives of mobile professionals. Mikko Ahonen's paper, "Building a Ubiquitous Artifact That Integrates Problem-Solving and Learning Processes to Support Creativity," reports from a doctoral project aimed at designing a prototypical ubiquitous information environment supporting learning and creativity. Finally, Majorkumar Govindaraju and David Sward in their paper, "Effects of Wireless Mobile Technology on Employee 
Work Behavior and Productivity: An Intel Case Study," present a case study on the practical experiences with the use of wireless connected notebooks, for example, in terms of the flexibility of employees and the increasing ubiquity of the notebooks.

\subsection{Panels}

The conference includes four panels on issues related to ubiquitous information environments. The first panel on ubiquitous computing for health and medicine by Chris Atkinson, Bonnie Kaplan, Kent Larson, Henrique M. G. Martins, Jay Lundell, and Martin Harris explores the nature and transformative capacity of ubiquitous computing in healthcare. The telematics panel by Ola Henfridsson, John King, Glenn Mercer, Dave Pavlich, and Walt Scacchi debates the emergence of ubiquitous vehicle information environments. In the third panel, Scott A. Shamp, Lev Gonick, Sirkka L. Jarvenpaa, and Pouline Middleton, discuss community-based wireless networks as a novel form of social innovation around the world. The panel focuses on the opportunities and challenges faced by social actors participating in this type of ubiquitous information environment. The fourth and final panel consists of practitioners from industry including Richard Braley (Fed Ex), Andy Fano (Accenture Technology Labs), John Light (Intel), and Ora Lassila (Nokia). Matt Germonprez joins these panelists in exploring the challenges and opportunities for ubiquitous information environments from their own vantage point.

\section{CONCLUSIONS}

The selected papers, invited keynote presentations, and panels provide a rich canvas for intense debate of the social aspects of ubiquitous information environments. In terms of technologies, the selection of papers presented here covers a diverse set of technologies such as mobile phones, remote diagnostics, RFID, and m-learning. Assuming that ubiquitous information environments spell strengthening of the ties between social action and technological properties, it is important to keep a sharp eye on both in order to fully grasp the issues.

In terms of coverage of possible research issues, the selected papers discuss the individual, the organizational, and to some extent the interorganizational levels (Lyytinen and Yoo 2002). One interesting observation that can be made, based on the research in the area of ubiquitous information environments in general and the papers in this collection in particular, is the relative lack of team level research. Perhaps the substantial body of research on teamwork and technology from organizational science, decision support systems, and CSCW can inform the discourse further. Both individual and organizational level studies seem to focus on unexpected consequences or paradoxes. One way of moving further could be to combine a deeper understanding of how classical research concerns play out in ubiquitous information environments with further development of novel theoretical elements explaining truly unique characteristics. The proceedings contain a rich set of papers exploring innovation and the role of standards and institutional arrangements in a broader context than the individual 
organization. Also, in terms of the distinction between the design, use, adoption, and impact of services, there is a fairly broad representation of issues, perhaps with less discussion of design issues (Lyytinen and Yoo 2002). This is, however, the primary focal point for much $\mathrm{HCI}$ and CSCW related research. There are, in this collection, no adoption studies across industries. As IFIP Working Group 8.2 mostly adopts qualitative research approaches, this is probably not unexpected. Regarding the enabling capabilities of infrastructures as well as their governance and control, the collection of papers represents research on both, but there is still a need to further reconnect research on privacy, trust, and awareness to this debate (Bellotti and Sellen 1993; Heath and Luff 2000; Lyytinen and Yoo 2002).

In the case of desktop information technology, much of the debate was constructed along the way jointly between theoretical considerations and innovative experimentation in practice. We would of course expect a similar coevolution of the debate into ubiquitous information environments. The primary aim of the conference is to forward the mobilization of core IFIP Working Group 8.2 expertise in this debate contributing to the analysis of turbulent socio-technical phenomena associated with wide-ranging adoption of mobile and wireless ICTs. As program chairs, we are very pleased with the variety and quality of submissions to this conference despite the relatively recent academic debate of ubiquitous information environments within our field. It is our hope that the conference and this conference proceedings will contribute actively to furthering the debate. We are certain that the debate will be enriched but also that the IFIP Working Group 8.2 community will shape the debate in its own unique way.

\section{REFERENCES}

Agar, J. Constant Touch: A Global History of the Mobile Phone, Cambridge: Icon Books, 2003. Baresi, L., Dustdar, S., Gall, H., and Matera, M. (Eds.). Ubiquitous Mobile Information and Collaboration Systems: Second CAiSE Workshop, Berlin: Springer-Verlag, 2004.

Barley, S. R., and Kunda, G. Gurus, Hired Guns, and Warm Bodies: Itinerant Experts in a Knowledge Economy, Princeton, NJ: Princeton University Press, 2004.

Bellotti, V., and Sellen, A. "Design for Privacy in Ubiquitous Computing Environments," in Proceedings of the Third European Conference on Computer-Supported Cooperative Work, G. DeMichelis, C. Simone, and K. Schmidt (Eds.), Dordrecht: Kluwer Academic Publishers, 1993, pp. 77-92.

Bjerrum, E., and Nielsen, O. Bliver man lidt småsaer af at have sit eget kontor? Nye arbejdsformer til debat (Does one become a bit odd by having one's own office? Debating new ways of working up), Copenhagen: JPBøger/Jyllands-Postens Erhvervsbogklub, 2003.

Boland, R., Tenkasi, R. V., and Te'eni, D. "Designing Information Technology to Support Distributed Cognition," Organization Science (5:3), 1994, pp. 456-475.

Brown, B., Green, N., and Harper, R. (Eds.). Wireless World, London: Springer-Verlag, 2001.

Brunsson, N., Jacobsson, B., and Associates. A World of Standards, Oxford, UK: Oxford University Press, 2000.

Bunting, M. Willing Slaves: How the Overwork Culture Is Ruling Our Lives, London: Harper Collins Publishers, 2004.

Caminer, D., Aris, J., Hermon, P., and Land, F. L.E.O.-The Incredible Story of the World's First Business Computer, London: McGraw-Hill Education, 1998.

Castells, M. The Rise of the Network Society, Oxford, UK: Blackwell, 1996. 
Cooper, G., Green, N., Murtagh, G. M., and Harper, R. "Mobile Society? Technology, Distance, and Precence," in Virtual Society? Technology, Cyberbole, Reality, S. Woolgar (Ed.), Oxford, UK: Oxford University Press, 2002, pp. 286-301.

Dix, A., and Beale, R. (Ed.). Remote Cooperation: CSCW Issues for Mobile and Teleworkers, London: Springer-Verlag, 1996.

Dourish, P. Where the Action Is: The Foundations of Embodied Interaction, Cambridge, MA: MIT Press, 2001.

Duffy, F., Laing, A., and Crisp, V. The Responsible Workplace: The Redesign of Work and Offices, Oxford, UK: Butterworth Architecture in association with Estates Gazette, 1993.

Funk, J. L. Global Competition Between and Within Standards: The Case of Mobile Phones, Chippenham, UK: Palgrave, 2002.

Heath, C., and Luff, P. Technology in Action, Cambridge, UK: Cambridge University Press, 2000.

Hinds, P., and Kiesler, S. (Ed.). Distributed Work, Cambridge, MA: MIT Press., 2002.

Hochschild, A. R. The Time Bind: When Work Becomes Home and Home Becomes Work, New York: Owl Books, 1997.

Hoete, A. (Ed.). ROAM: Reader on the Aesthetics of Mobility, London: Black Dog Publishing, 2003.

Jarvenpaa, S. L., and Leidner, D. E. "Communication and Trust in Global Virtual Teams," Organization Science (10:6), Special Issue: Communication Processes for Virtual Organizations, 1999, pp. 791-815.

Kakihara, M. Emerging Work Practices of ICT-Enabled Mobile Professionals, unpublished Ph.D. Thesis, The London School of Economics and Political Science, 2003 (available online at http://is.lse.ac.uk/research/theses/).

Katz, J. E., and Aakhus, M. (Eds.). Perpetual Contact, Cambridge, UK: Cambridge University Press, 2002.

Kopomaa, T. The City in Your Pocket: Birth of the Mobile Information Society (translated by T. Snellman), Helsinki: Gaudeamus, 2000.

Kunda, G. Engineering Culture. Control and Commitment in a High-Tech Corporation, Philadelphia: Temple University Press, 1992.

Laing, A., Duffy, F., and Jaunzens, D. New Environments for Working: The Re-design of Offices and Environmental Systems for New Ways of Working, Watford, UK: Construction Research Communications Ltd., 1998

Lasen, A., and Hamill, L. (Eds.), Mobile World: Past, Present and Future, London: SpringerVerlag, 2005.

Ling, R. The Mobile Connection: The Cell Phone's Impact on Society, Amsterdam: Morgan Kaufmann, 2004.

Ling, R. R., and Pedersen, P. E. (Eds.). Mobile Communications: Re-negotiation of the Social Sphere, London: Springer-Verlag, 2005.

Ljungberg, F. Networking, unpublished Ph.D. thesis, Göteborg University, 1997.

Lovink, G., and Gerritzen, M. (Eds.). Mobile Minded, Amsterdam: BIS Publishers. 2002.

Lyytinen, K., and Yoo, Y. "The Next Wave of Nomadic Computing: A Research Agenda for Information Systems Research," Information Systems Research (13:4), 2002, pp. 377-388.

Lyytinen, K., Yoo, Y., Varshney, U., Ackerman, M. S., Davis, G. B. Avital, M., Robey, D., Sawyer, S., and Sørensen, C. "Surfing the Next Wave: Design and Implementation Challenges of Ubiquitous Computing Environments," Communications of the AIS (13), 2004, pp. 697-716.

Malone, T. W. The Future of Work: How the New Order of Business Will Shape Your Organization, Your Management Style, and Your Life, Boston: Harvard Business School Press, 2004.

McCollough, M. Digital Ground: Architecture, Pervasive Computing, and Environmental Knowing, Cambridge, MA: MIT Press, 2004. 
Orr, J. E. Talking About Machines: An Ethnography of a Modern Job, Ithaca, NY: Cornell University Press, 1996.

Rheingold, H. Smart Mobs, New York: Perseus Books, 2002.

Schiller, J., and Voisard, A. Location-Based Services, San Francisco: Morgan Kaufmann, 2004.

Schultze, U., and Orlikowski, W. "A Practice Perspective on Technology-Mediated Network Relations: The Use of Internet-Based Self-Serve Technologies," Information Systems Research (15:1), 2004, pp. 87-106.

Sørensen, C., and Pica, D. "Tales from the Police: Mobile Technologies and Contexts of Work." Information and Organization (15:3), 2005 (forthcoming).

Sproull, L., and Kiesler, S. Connections: New Ways of Working in the Networked Organization, Cambridge, MA: MIT Press, 1993.

Umar, A. Mobile Computing and Wireless Communications: Applications, Networks, Platforms, Architectures, and Security, NGE Solutions, 2000 (http://www.ngesolutions.com).

Urry, J. Global Complexity, Cambridge, UK: Polity, 2003

Urry, J. "Mobile Sociology," British Journal of Sociology (51:1), 2000, pp. 185-203.

Weiser, M. "The Computer for the $21^{\text {st }}$ Century," Scientific American, 1991, pp. 94-110.

Weiser, M. "Ubiquitous Computing," 1999 (available online at http://www.ubiq.com/hypertext/ weiser/UbiHome.html).

Wiberg, M. In Between Mobile Meetings: Exploring Seamless Ongoing Interaction Support for Mobile CSCW, unpublished Ph.D. Dissertation, Department for Informatics, Umeå University, 2001.

Wiredu, G. Mobile Computing in Work-Integrated Learning: Problems of Remotely Distributed Activities and Technology Use, unpublished Ph.D. dissertation, London School of Economics, 2005 (available online at http://is.lse.ac.uk/research/theses/).

Yates, J. Control through Communication: The Rise of System in American Management, Baltimore: The Johns Hopkins University Press, 1989.

Yoo, Y., and Alavi, M. "Emergent Leadership in Virtual Teams: What Do Emergent Leaders Do?," Information and Organization (14:1), 2004, pp. $27-58$.

\section{ABOUT THE AUTHORS}

Carsten Sørensen is a senior lecturer in Information Systems at The London School of Economics and Political Science, United Kingdom. He holds a B.Sc. in mathematics, an M.Sc in computer science, and a Ph.D. in information systems from Aalborg University, Denmark. Carsten has, through the past 16 years, been affiliated with a number of Danish, Swedish, and British institutions. He has also been actively engaged with executive education and has consulted for a range of organizations, including Microsoft, Orange, Caja Madrid, Kommunedata, and Netonomy. Carsten is studying how ICT shapes and is shaped by emerging working practices and organizational forms and, most recently, mobile technologies for organizational efficiency. He has been involved in research on mobile computing since the mid-1990s and is was one of the founding members of the Internet Project. In 2001, Carsten initiated the mobility@Ise research network in mobile interaction (http://mobility.lse.ac.uk/), with the goal of drawing together academics and practitioners. Carsten has extensive EU and international project experience. Since 1997, he has been Research Director of Laboratorium for Interaction Technology (http://laboratorium.htu.se) at Trollhättan Uddevalla University, Sweden. He is on the editorial board for Information and Organization and The e-Service Journal. Carsten has served as organizer, chair, associate editor, track chair, and track co-coordinator for a number of international conferences, including the International Conference on Information Systems, the Hawaii International Conference on System Sciences, the European Conference on Information 
Systems, and the Information Systems Research Seminar in Scandinavia. Carsten can be reached by e-mail at c.sorensen@lse.ac.uk.

Youngjin Yoo is an associate professor in Information Systems and the Lewis-Progressive Chair in Management at the Weatherhead School of Management, Case Western Reserve University. He holds a Ph.D. in information systems from the University of Maryland. He received his MBA and B.S. in Business Administration from Seoul National University in Seoul, Korea. His research interests include ubiquitous computing, knowledge management, the role of information technology for virtual teams, and IT-based new organizational forms. His work has been published in leading academic journals including Information Systems Research, MIS Quarterly, Academy of Management Journal, Journal of Strategic Information Systems, Communications of the ACM, Information and Organizations, and International Journal of Organizational Analysis. He has published several book chapters and presented his work at national and international research conferences, including International Conference on Information Systems, Americas Conference on Information Systems, and Hawaiian International Conference on Systems Sciences. Youngjin has researched leading companies including NASA, Andersen Consulting, Ernst and Young Center for Business Knowledge, IDEO, Gehry and Partners, University Hospitals in Cleveland, Lotus, Parker Hannifin, Poly One, and the Department of Housing and Urban Development. He was the first nonengineering faculty member to be selected as summer research fellow at the NASA Glenn Research Center in 2001. $\mathrm{He}$ has received research grants from the National Science Foundation and NASA. He is an associate editor of Information Systems Research and on the editorial board of Organization Science, Journal of AIS, and Information and Organization. Youngjin can be reached by e-mail atyyoo@case.edu. 


\section{Part 1}

Keynotes 